Article

\title{
Spatial Multi-Objective Land Use Optimization toward Livability Based on Boundary-Based Genetic Algorithm: A Case Study in Singapore
}

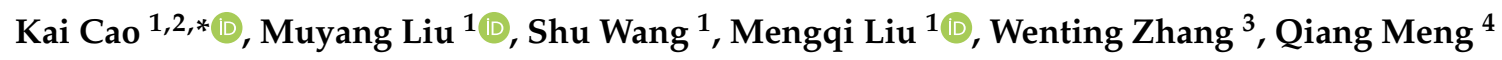 \\ and Bo Huang ${ }^{5}$ \\ 1 Department of Geography, National University of Singapore, Singapore 119077, Singapore \\ 2 School of Information Systems, Singapore Management University, Singapore 188065, Singapore \\ 3 College of Resources and Environment, Huazhong Agricultural University, Wuhan 430070, China \\ 4 Department of Civil and Environmental Engineering, National University of Singapore, \\ Singapore 119077, Singapore \\ 5 Department of Geography and Resource Management, The Chinese University of Hong Kong, \\ Hong Kong, China \\ * Correspondence: geock@nus.edu.sg or kaicao@smu.edu.sg
}

Received: 8 December 2019; Accepted: 30 December 2019; Published: 14 January 2020

\begin{abstract}
In this research, the concept of livability has been quantitatively and comprehensively reviewed and interpreted to contribute to spatial multi-objective land use optimization modelling. In addition, a multi-objective land use optimization model was constructed using goal programming and a weighted-sum approach, followed by a boundary-based genetic algorithm adapted to help address the spatial multi-objective land use optimization problem. Furthermore, the model is successfully and effectively applied to the case study in the Central Region of Queenstown Planning Area of Singapore towards livability. In the case study, the experiments based on equal weights and experiments based on different weights combination have been successfully conducted, which can demonstrate the effectiveness of the spatial multi-objective land use optimization model developed in this research as well as the robustness and reliability of computer-generated solutions. In addition, the comparison between the computer-generated solutions and the two real planned scenarios has also clearly demonstrated that our generated solutions are much better in terms of fitness values. Lastly, the limitation and future direction of this research have been discussed.
\end{abstract}

Keywords: spatial multi-objective land use optimization; boundary-based genetic algorithm; livability; accessibility; smart planning; Singapore

\section{Introduction}

Land use optimization, as one important kind of resource allocation, can be defined as the process of allocating different activities to various geographical units, such as residential land, industrial land, recreational facility, green land, etc. Therein, different objectives will result in different land use allocations and consequently, the achievement of multiple objectives simultaneously will result in quite a complicated trade-off process. For instance, with the notion of sustainability, three different objectives are strived for, such as environmental preservation, economic prosperity, and social equity. It is obvious that for planners and policymakers it is difficult to achieve these objectives simultaneously by making use of traditional methods. Therefore, it is necessary to look for methods in which multiple objectives could be considered effectively and simultaneously, despite its complexity.

Both concepts of sustainability and livability have been widely discussed in land use planning and optimization, which is to achieve the ultimate goal of reaching sustainability and improving livability. 
Gough [1] described the overlap and separation between these two concepts and demonstrated the complementarity and conflict between sustainability and livability. Sustainability considers the long-term consequences of the development more, which aims to meet the current generations' needs without threatening the lives of future generation [2]. In contrast, livability concentrates on the idea of "now" and "here", which refers to more explicit goals and immediate interference [3]. Pacione [4] states that urban livability is a relative term which takes "place, time, and purpose of the assessment and on the value system of the assessor" into consideration. This definition of livability emphasizes human and environment interaction.

How to optimize the land use allocation has been discussed in various studies towards long-term sustainability in the past. Besides the idea of long-term sustainability, promoting current livability to create a desirable living environment should also be seen as another appealing direction or objective in land use planning and optimization. For land use planning and optimization, to raise livability is to create a more desired and livable environment through the allocation of land use types and reasonable use of natural resources while allowing the environment, economy, and society to have superior performance. It is necessary to not only endorse long term sustainability but to achieve the local livability preference through reasonable planning. This research aims to study how livability could quantitatively contribute to the understanding and modelling of spatial multi-objective land use optimization. The concept of livability in the context of land use planning and optimization is comprehensively reviewed and interpreted in this research, and then a spatial multi-objective optimization model based on boundary-based genetic algorithm is adapted and utilized to accommodate these interpreted objectives and constraints for optimizing the land use scenarios in the case study of Central Region of Queenstown Planning Area in Singapore towards livability. Lastly, the experiments results, reflections, conclusions and future research are also covered in the remainder of the manuscript.

\section{Literature Review}

Land use optimization has been broadly studied in the past decades towards various concerns or objectives [5-14]. However, there has not been many studies specifically on the livability oriented land use optimization except some general discussions and interpretation on livability from various perspectives of researchers. Balsas [15] presented an exploratory study of the key performance indicators (KPI) for measuring the livability of urban centres. By describing a social, economic, or physical reality using a measure or a set of measures, and determining the performance of an act are the responsibilities of an indicator [16]. Six dimensions of performance were used in Balsas [15] KPI, including vitality, sense, fit, access, control, and viability. The first five dimensions were adopted from Lynch [17]'s perception of what makes a livable city. While viability refers to the ability of an urban to appeal itself and bring in investment, vitality points out whether the city can remain alive or not [15]. Antognelli and Vizzari [18] believed that the key for assessing the urban livability is through using ecosystem service and urban service, which can affect the landscape planning as well as the policy-making process. They had developed a livability spatial assessment model (LISAM), which both local access to service and its significance to stakeholders were considered. Ecosystem service (ES) mostly comes from or had natural resources as inputs to benefit human society; urban service (US) considers more socio-economic and public services and facilities [19,20]. The model with spatial indices weighting and aggregation was generated from spatial accessibility modelling, and stakeholders' interviews were applied to a service weight calculation (AHP), which was used for mapping the ecosystem service and urban services accessibility to examine the livability of the study area [18]. Wang et al. [21] conducted a comparative study with a focus on the livable level integrated index (LLII) to evaluate the livability for global cities. The index was derived according to three aspects, including social development, living standard, and environmental quality. The LLII was assessed by a linear weighted sum approach. Higgs et al. [22] proposed a spatial urban livability index for examining the relationship with travel behaviour where walkability, social infrastructure mix, public 
transport access, large public open space, affordable housing, and local working opportunities are the main indicators.

In addition to a variety of livability index systems proposed by different researchers based on different contexts and levels of details, there have also been many studies that are focusing on how urban livability can be improved. Accessibility is one of the main targets for increasing the living quality. The level of accessibility can be measured from different aspects such as accessibility to transportation facilities, to civil and community facilities, or green spaces. Litman [23] argues in this research that accessibility examination can bring positive effect to all the aspects of sustainability, which could also improve community livability in the social aspects. Similarly, Miller and Witlox [24] also depicted accessibility as a significant factor for livability, which contributes significantly to urban and transportation planning. On the other hand, La Rocca [25] introduced that soft mobility, which includes all kinds of non-motorized transport, is able to optimize the urban livability due to its "zero-impact", which can ease the environmental burden (level of noise, air pollution, and traffic congestion) created by human activities. Besides accessibility, compactness is another issue that has been broadly discussed. High density and compact land use is able to lead to efficient lifestyles. Urban compactness aims to make the best use of the land resource without wasteful sprawl in the metropolitan [10]. Abdullahi et al. [26] integrated multi-criteria decision-making, Bayes theorem, and RADAR images to assess the city compactness of Kajang City in Malaysia. Ward et al. [27] in their research combined cellular automata and spatial optimization for evaluating urban changes, and they deliberately considered spatial compactness and accessibility in the optimization model for pursuing higher livability in the cities. Moreover, spatial compatibility usually considers the relationship of adjacent land use types [7,28], which is also quite commonly used in addressing land use optimization issues. Land uses scenarios with good compatibility require that each functional unit would have the most positive interaction with their neighbouring units [29]. It is evident that the spatial compatibility of different land use units (e.g., grid or parcels) could contribute to the harmony and livability of the entire area. Zhang et al. [30] estimated compatibility index between different land uses for simulating the spatial multi-objective spatial optimization with multi-agent system and genetic algorithm. Haque and Asami [31] have successfully tried to maximize land price and reduce incompatibility when generating feasible land use plans. It is obvious that higher compatibility between land use types would lead to a more livable environment since the compatibility index is expected to engage with the human-environment interaction in the land use planning process. In this research, compatibility scores have been obtained and utilized to be one of the major objectives in our model and experiments for generating compatible land use planning scenarios.

Land use optimization problems are rather complex, as such decisions must be made not only on what to allocate (selection of land use types), and on how much to allocate, but also on where to allocate. Therefore, the model for integrating these spatial multi-objectives and algorithms for addressing this kind of spatial optimization problem might be critical bottlenecks. In the past, lots of multi-objective optimization problems including land use optimization problems were solved by linear programming (LP) [32]. However, one of the problems in that is determining the relative weights of each objective. At the same time, the "Pareto front" method brought the other mode to consider the multi-objective optimization problems, which was derived from Pareto's original work [33]. One characteristic of the "Pareto front" method is the independence of the objectives. Until now, it has been broadly and successfully utilized for solving spatial multi-objective spatial optimization problems [10,34,35]. A drawback is the low efficiency of the optimization process. Another kind of effective method is the abovementioned "weighted-sum" method. Although it cannot yield non-convex optimal solutions, it has still been commonly used because of its simplicity and effectiveness for most of the multi-objective optimization problems $[6,9,36,37]$. In this research, the goal programming and weighted-sum methods are used to construct the land use optimization model.

All the multi-objective models mentioned above create a need for efficient optimization algorithms for addressing various land use optimization problems while the deterministic optimization turns to 
be impossible or inappropriate given the complexity of spatial optimization problems. A switch can be observed from strict optimization to the use of heuristics. Genetic algorithm (GA), as one kind of effective heuristic methods for optimization problems, has also been successfully applied in various domains and studies [38]. Stewart et al. [37] have taken advantage of GA to perform multi-objective land use allocation in a small research area based on grids. Janssen, van Herwijnen, Stewart and Aerts [36] have also utilized GA for land use allocation on a small area (20 by 20 cells). Cao et al. [6,10,12] have successfully and effectively employed various kinds of GA to address land use optimization problems. In this research, a boundary-based GA, which follows the principles of traditional GA and adapted from Cao, Huang, Wang and Lin [6], is integrated into a land use optimization model to tackle the land use optimization problem towards livability in the case study of Singapore.

\section{Methodology}

\subsection{Formulation of a Spatial Multi-Objective Optimization Model}

The selection of the spatial data model is vital when building a spatial multi-objective optimization model. In this research, vector data is utilized because of its better representation of land use and parcel for addressing planning problems compared to raster data [12]. An area consists of $N$ vectors with $K$ different land use types is formed. For each vector $i$, it equals $k_{i}$ when the land use category $k$ is assigned to it.

In general, the values of all the objectives are dependent on the distribution of land use type $k$ for each vector $i$. Hence, $B_{i k}$ is set as a parameter generally representing the value of each objective. In addition, it is assumed that $x_{i k}=1$ when a land use category $k$ is assigned to the vector $i$, otherwise $x_{i k}=0$ when vector $i$ is not covered by land use type $k$.

Maximize:

$$
\sum_{k=1}^{K} \sum_{i=1}^{N} B_{i k} x_{i k}
$$

Subject to:

$$
\begin{gathered}
\sum_{k=1}^{K} x_{i k}=1 \quad \forall k=1, \ldots, K ; i=1, \ldots, N . \\
x_{i k} \in\{0,1\} .
\end{gathered}
$$

These two formulas ensure that there must be one and only one kind of land use type for each vector, since the binary variables $x_{i k}$ can only be 0 or 1 .

Furthermore, weighted-sum method is employed for formulating the spatial multi-objective optimization model.

$$
f_{o b i}=\sum_{o=1}^{O} \sum_{k=1}^{K} \sum_{i=1}^{N} \alpha_{o} B_{o i k} x_{o i k}
$$

where

$$
\forall 0=1, \ldots, O,
$$

$B_{\text {oik }}$ is the value of each objectives $o$ calculated based on the allocation of land use type $k$ for each vector $i$.

$\alpha_{o}$ are the weights of the objectives $o$.

In order to make sure the scale of all these objectives are the same and the weights could reasonably reflect the planners' or decision-makers' preference on various objectives, prior to running 
the weighted-sum method for the spatial multi-objective optimization modelling, the maximum value and minimum value of each objective are acquired for the normalization of each objective.

$$
f_{o b i}=\sum_{o=1}^{O} \alpha_{o}\left[\frac{f_{o b i o}-I_{o}}{T_{o}-I_{o}}\right],
$$

where

$f_{\text {obio }}$ is the value of the objectives o;

$T_{o}$ is the maximum value of the objectives 0 ;

$I_{0}$ is the minimum value of the objectives 0 .

\subsection{Boundary Based Genetic Algorithm}

This research adapts a boundary-based GA, which has demonstrated its effectiveness and efficiency in earlier studies [6], to search for the optimal/near-optimal solutions of land use scenarios for support the planning and relevant decision-making process. In a traditional GA, 'Initial population', 'Fitness function', 'Selection', 'Crossover', and 'Mutation' are the key five procedures, the boundary strategy is specifically incorporated into a traditional GA to increase the possibility of generating more reasonable solutions given the complexity of a spatial optimization issue. After times of experiments in this research, the phase 'Crossover' has not been significantly and positively contributing to the searching of optimal/near-optimal solutions given the characteristics of the multi-objective land use optimization model we have defined. Therefore, the 'Crossover' operator was removed, and one extra random 'Mutation' operator was included, which is also able to account for the diversity of solutions during the optimization process.

\subsubsection{Chromosome Representation}

To represent the land use parcels in the GA, a chromosome is assumed as a scenario of land use planning scenario, which consists of a list of gene, and the ID of each gene can represent the location of a land parcel or feature and the value of each gene can represent the land use type allocated into the land parcel or feature.

\subsubsection{Initialization of Parent Solutions}

As the first step of GA procedures, initialization of parent solutions is a vital process that influences the overall effectiveness and efficiency of GA convergence. To facilitate the procedure for searching for optimal solutions, an initial population with relatively more reasonable land use scenarios are undoubtedly better than an initial population with totally randomly land use scenarios. In this research, the boundary-based strategy [6] has been employed and in total 1000 solutions have been generated as the initialized parent solutions.

\subsubsection{Boundary-Based Mutation Operator}

Based on the parent solutions, the boundary-based strategy is employed to the mutation operator to facilitate the running and convergence of GA in the experiments. The boundary-based mutation operator is to randomly find a polygon where its land use is different from at least one polygon adjacent to it, and change the land use category of the polygon into the land use of the one that adjacent to and different from itself. Apparently, this boundary-based mutation operator is able to not only keep the diversity of the offspring solutions but also make the offspring solutions more reasonable, which has already been proved and utilized in many successful existing studies. 


\section{Case Study}

\subsection{Introduction to the Study Area and Contexts}

Singapore is an island city-state of $721.5 \mathrm{~km}^{2}$ with a population of 5.64 million [39] which is located in Southeast Asia. Singapore's land use and allocation are governed by its master plan. To support a larger population (6.5 6.9 million by 2030) proposed by the Population White Paper [40], land use plan needs to reclaim additional land and intensify new developments. It is necessary to promote better livability in a country with high population density. Since it is not applicable to refine the whole state with a single urban planning project, One North, a subzone lies in the Central Region of Queenstown Planning Area in Singapore is selected as the pilot study area.

One North is an integrated R\&D (Research and Development) hub and high technology cluster located in the Central Region of Queenstown, Singapore. In order to attract high-tech labour, land use allocation with higher livability around One North is needed. Queensway subzone, located at the eastern wings of One North (see Figure 1), is planned as one of the residential zones around the high-tech enterprises. The Queensway subzone is divided into 221 polygons for further land use optimization.

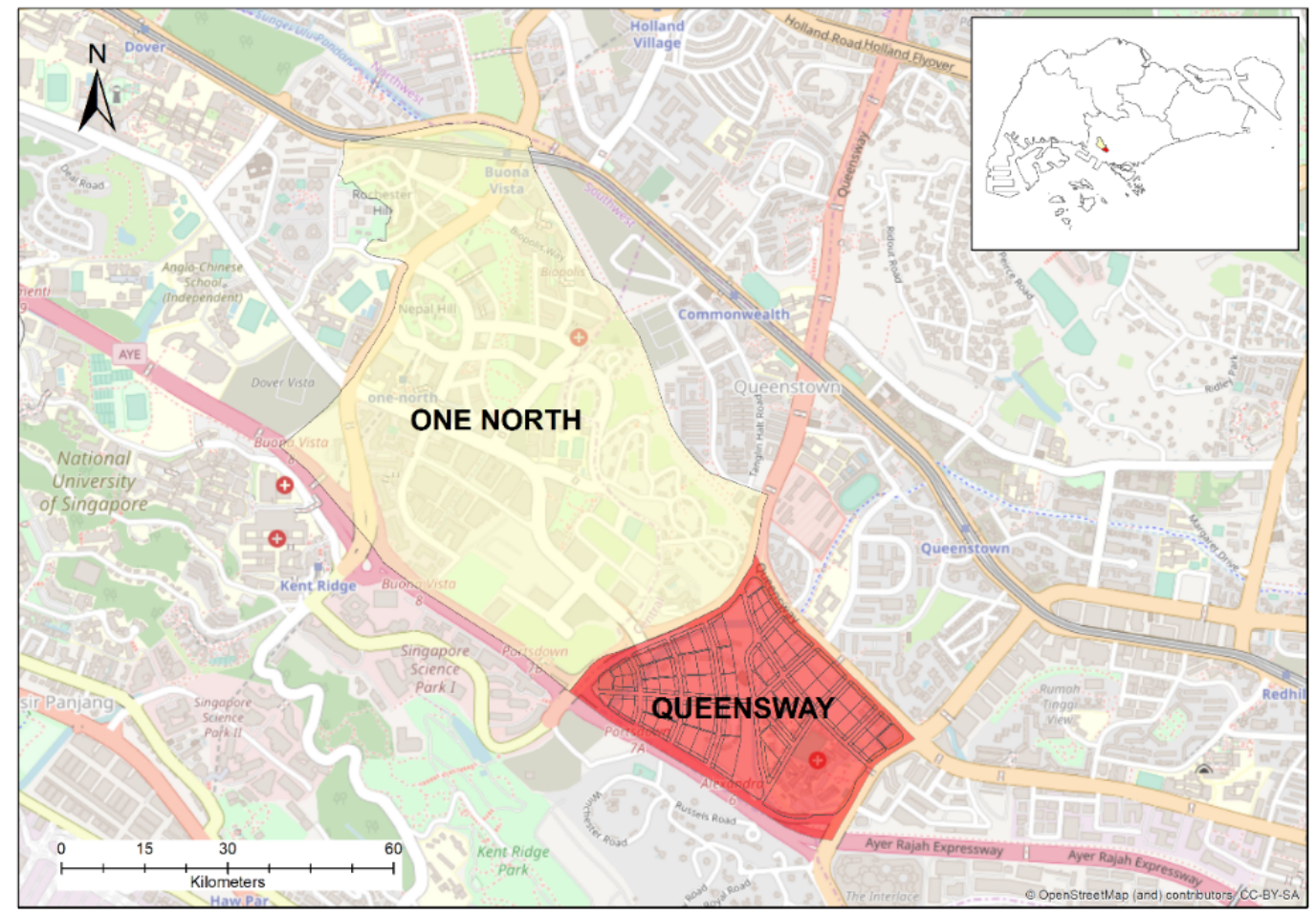

Figure 1. The location of One North and Queensway in Singapore.

The Land use plan in Queensway Planning Area faces several challenges:

1. One North is also considered to be Singapore's Silicon Valley-an integrated scientific and technology innovation centre. Besides compact and diverse land use strategies, the development shall promote pedestrian mobility and accessibility to enhance the livability as well as working efficiency. Within this development, communities and businesses can be clustered within walking distance to save commuting cost. Different urban functions and facilities shall be integrated with streets and public spaces to create a lively setting and enhance the chances of commutations and knowledge spillover. Accordingly, compactness, as well as good accessibility to transportation, working places, and other facilities would be highlighted for jobs-housing balance and promoting livability. 
2. With the idea of work-live-play-learn development in One North, inevitably, various land uses such as commercial, residential, business, and institutional need to merge in such a dense place harmoniously. Thus, the challenge will be how to integrate different land uses while maintaining the livability and vibrancy of the site as well. Namely, the objective is to find out the most compatible land use plan that could contribute to a more diverse and vibrant community.

To address the above challenges, maximization of accessibility and maximization of compatibility should be considered in this case study to improve the livability of the One North Subzone. The land use types concerned in this project are residential, commercial, residential \& commercial, education, hospital, office, $\mathrm{SOHO}$, and green space, which are refined from the point of interest (POI) categories of Singapore's 2014 Master Plan. SOHO stands for small office, home office. It is a hybrid apartment for residential and commercial purposes and allows people to work and live in the same house. Accessibility tackles the access from residential areas to other land use types including commercial ("residential and commercial" is recognized as commercial area when calculating the accessibility), education, hospital, office or $\mathrm{SOHO}$, and green space. By improving the accessibility to these areas, the overall livability can be enhanced since it is more convenient for people to go to places they wish to go. Compatibility is calculated based on the compatibility table, in which each land use type has records representing the level of its compatibility to all these land use types. At the same time, there should also be some constraints considered in the optimization, such as the reserved land use parcels, and a minimal amount of different land use types in different solutions, which will be introduced in the following sections with details.

\subsection{Objectives and Constraints}

\subsubsection{Maximization of Accessibility}

Euclidean distance from the residential area to other facilities is applied to qualify the accessibility in this research. To realize the objective of maximizing the accessibility, distance between the infrastructures and the residential land use should be minimized as following:

Minimize:

$$
\sum_{l=1}^{L} \operatorname{average}\left(d_{r l}\right),
$$

where

$$
\forall d_{r l} \in d\left(i_{\forall k \in r}, j_{\forall k \in l}\right) ; \exists i, j \in N .
$$

There are $L$ kinds of infrastructures considered in the accessibility objective, i.e., commercial consisting of 'commercial' and 'residential and commercial', 'education', 'hospital', 'office', consisting of 'office' and 'SOHO', Green Space. Besides, the Residential land use $r$ includes 'Residential', 'Residential \& Commercial' and 'SOHO'. For each type of infrastructure $l$, minimizing the average distance average $\left(d_{r l}\right)$ from the residential land use $r$ to all the infrastructure $l$ is the way to realize the objective of maximizing the accessibility. The distance between two vectors is calculated as the Euclidean distance between the centroid points.

\subsubsection{Maximization of Compatibility}

The compatibility of a land use plan is regarded as the relationships among various land use types of an overall land use layout. A land use scenario with good compatibility requires that each unit would have the most positive interaction with its adjacent units [29].

To describe the compatibility between different land use types, a survey listing the 8 types of land uses is designed for pair-wise comparison. The survey requires experts to rate the compatibility value from 1 to 9 for each two land use types, while 1 means "extremely incompatible" and 9 means "extremely compatible". With the help of 22 experts from the field of urban planning, the compatibility score between each pair of land use types is calculated as shown in Table 1. For any land use scenarios 
composed of these 8 land use types, the overall compatibility is the sum of the compatibility between each pair of adjacent units.

Table 1. Compatibility score between each pair of land use categories.

\begin{tabular}{|c|c|c|c|c|c|c|c|c|}
\hline & \multicolumn{3}{|c|}{ CommercialResidential Office } & \multirow{2}{*}{$\begin{array}{c}\begin{array}{c}\text { Residential } \\
\text { and } \\
\text { Commercial }\end{array} \\
7.5\end{array}$} & \multirow{2}{*}{$\begin{array}{c}\text { Green } \\
\text { Space }\end{array}$} & \multirow{2}{*}{$\begin{array}{c}\text { Education } \\
4.1\end{array}$} & \multirow{2}{*}{$\begin{array}{c}\text { Hospital } \\
4.2\end{array}$} & \multirow{2}{*}{$\begin{array}{c}\text { SOHO } \\
7.4\end{array}$} \\
\hline Commercial & 8.8 & 7.3 & 7.9 & & & & & \\
\hline Residential & 7.3 & 8.7 & 6 & 7.1 & 8.4 & 7.8 & 6.2 & 7 \\
\hline Office & 7.9 & 6.8 & 8.6 & 6.3 & 7.1 & 5.6 & 5 & 7.1 \\
\hline $\begin{array}{l}\text { Residential } \\
\text { and }\end{array}$ & 7.5 & 7.1 & 6.3 & 8.6 & 7.3 & 4.7 & 4.7 & 7.4 \\
\hline Commercial & & & & & & & & \\
\hline $\begin{array}{l}\text { Green } \\
\text { Space }\end{array}$ & 7.4 & 8.4 & 7.1 & 7.3 & 8.2 & 7.7 & 6.9 & 7.1 \\
\hline Education & 4.1 & 7.8 & 5.6 & 4.7 & 7.7 & 8.4 & 5.3 & 5 \\
\hline Hospital & 4.2 & 6.2 & 5 & 4.7 & 6.9 & 5.3 & 8.1 & 4.7 \\
\hline SOHO & 7.4 & 7 & 7.1 & 7.4 & 7.1 & 5 & 4.7 & 8.6 \\
\hline
\end{tabular}

The value of compatibility objective is calculated based on the compatibility table (Table 1 ), whose value varies depend on the land use types of two adjacent vectors. For each vector $i$, it has $M$ neighbors $j . k_{i}$ and $k_{j}$ represent the land use types of the vector $i$ and its neighbor $j$. According to the compatibility table, Comptibility $y_{k_{i} k_{j}}$ represents the compatibility for each vector $i$ with one of its neighbor $j$, which equals to the compatibility value between $k_{i}$ and $k_{j}$. Hence, the objective of compatibility can be formulated as follows:

Maximize:

$$
\sum_{i=1}^{N} \sum_{j=1}^{M} \text { Comptibility }_{k_{i} k_{j}}
$$

where

$$
\forall k=1, \ldots, K ; i=1, \ldots, N ; j=1, \ldots, M .
$$

\subsubsection{Constraints}

In this case study, the hospital and central green areas are the conservation districts (as can be seen in Figure 2). As a residential district around the high-tech enterprises, a minimal requirement of Residential land use including Residential, Residential \& Commercial, $\mathrm{SOHO}$ is set as $50 \%$ of the whole area. Besides, a minimal area demand for other land use categories is also set to provide the diversity of life in the area as follows (see Table 2). With the consideration of the conservation area, there are totally 218 polygons for further optimization.

Table 2. The minimal area proportion of each kind of land use.

\begin{tabular}{ccc}
\hline Land Use Type & Composition & $\begin{array}{c}\text { Minimal Need of } \\
\text { Area Proportion }\end{array}$ \\
\hline Commercial & 'Commercial' + 'Residential and Commercial' & $10 \%$ \\
Residential & 'Residential' + 'Residential and Commercial' + 'SOHO' & $50 \%$ \\
Office & 'Office' + 'SOHO' & $15 \%$ \\
Education & 'Education' & $2 \%$ \\
Only Office & 'Office' & $15 \%$ \\
Only Residential & 'Residential' & $2 \%$ \\
Only Commercial & 'Commercial' & $5 \%$ \\
\hline
\end{tabular}




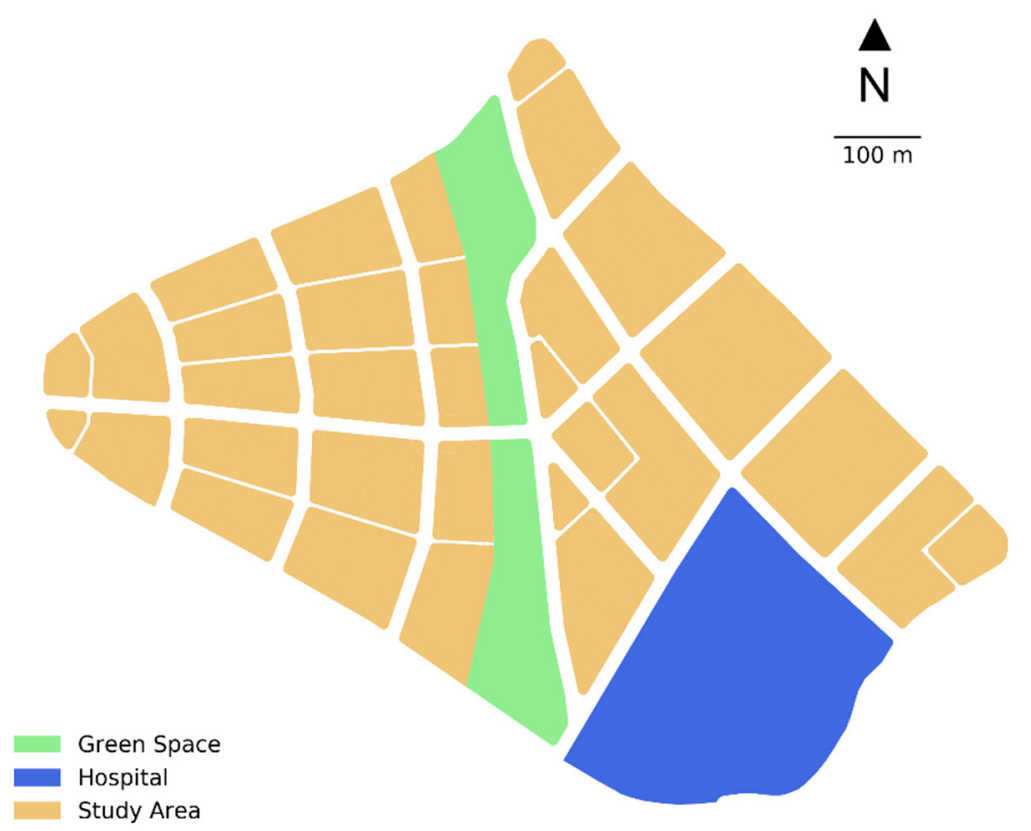

Figure 2. Research Area and Conservation Area.

\subsection{Experiments and Results}

\subsubsection{Experiments Based on Equal Weights}

After running the algorithm for 10 times with 10,000 as the number of iterations and equal weights for both the two objectives on a laptop computer with an Intel(R) Core (TM) i5-8250U CPU@1.6 GHz and 8 GB RAM, the 10 fitness values are obtained below. The fitness values (see Table 3) are computed based on equal weights combination of the two objectives, i.e., accessibility and compatibility mentioned above. In all these experiments, the larger the fitness values are, the better the result is.

Table 3. Fitness value of the solutions based on equal weights.

\begin{tabular}{ccccccccccc}
\hline Solution & 1 & 2 & 3 & 4 & 5 & 6 & 7 & 8 & 9 & 10 \\
Fitness Value & 1.4989 & 1.4985 & 1.4991 & 1.4979 & 1.4979 & 1.4984 & 1.4984 & 1.4979 & 1.4979 & 1.4979 \\
\hline
\end{tabular}

It is evident that the fitness values are quite close, which could somewhat demonstrate the stability and robustness of the model and experiments.

In addition, the solution maps are also shown below-these solution maps are also quite similar with some minor differences (see Table 4). In addition, the convergence curve for the first experiment (see Figure 3), which is quite same as the convergence curves of the other nine experiments, is also shown below to demonstrate the convergence of the running of the algorithm. These results can also demonstrate the robustness and stability of our experiments as well as the effectiveness of the adapted boundary-based GA. These computed planning scenarios could further support the planning and decision- making process, especially raise some debates and negotiation while a variety of stakeholders are involved. 
Table 4. Results of experiments based on equal weights.

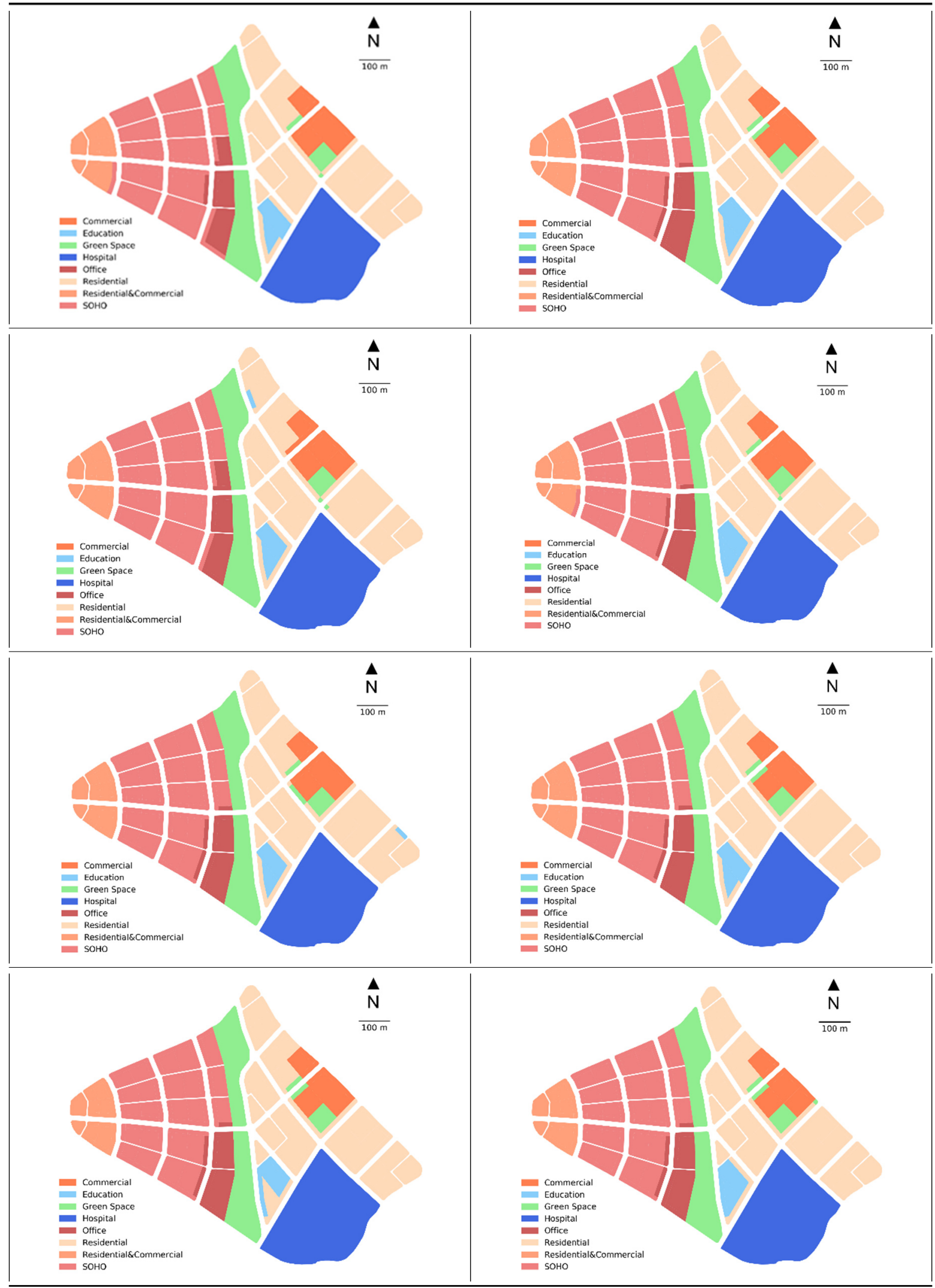


Table 4. Cont.
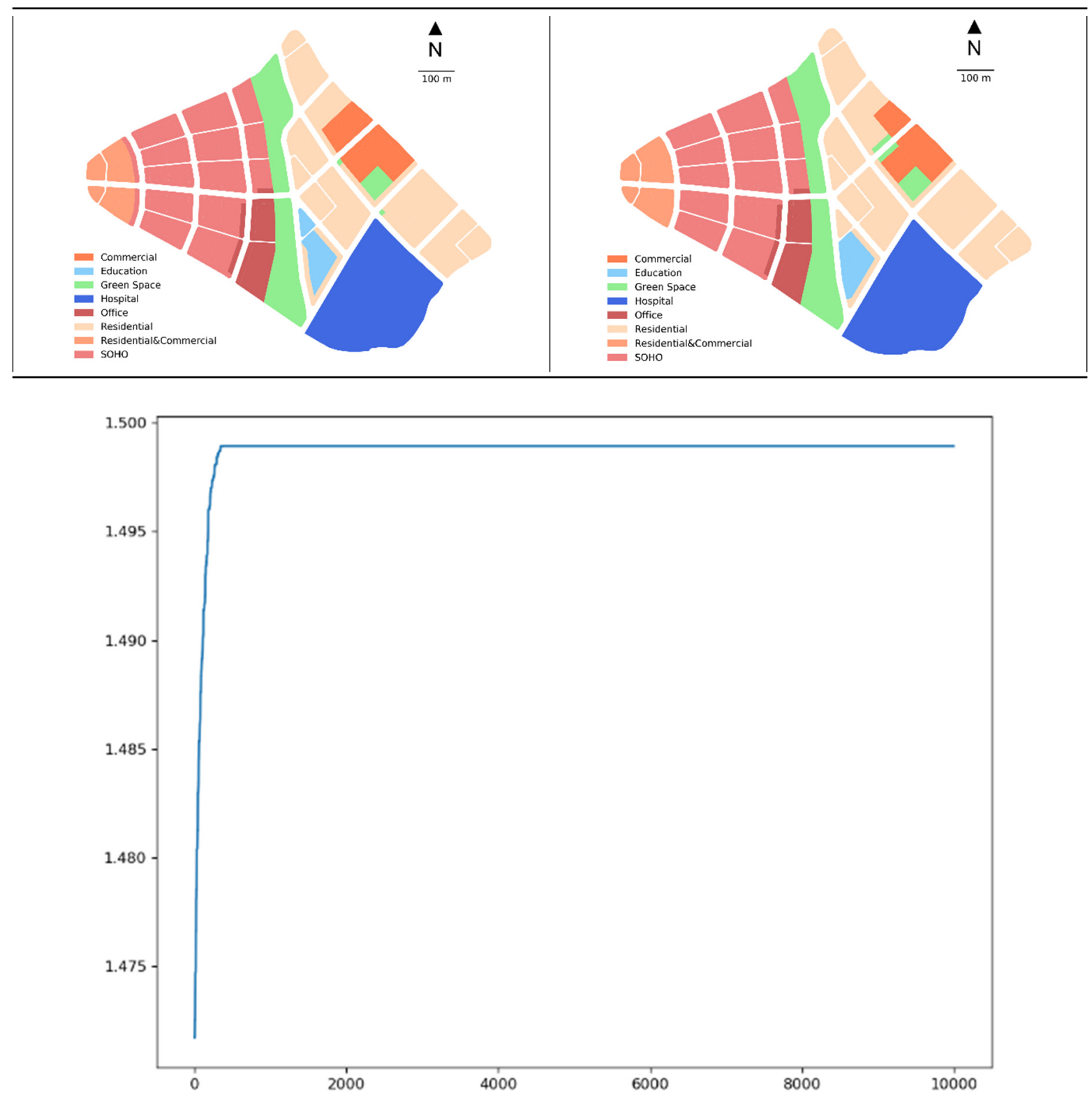

Figure 3. Convergence curve of the first experiment ( $x$ axis refers to the number of iterations, and $y$ axis refers to the fitness value).

\subsubsection{Experiments Based on Different Weights Combination}

After running the algorithm for 10 times with 10,000 as the number of iterations and 2 and 1 as the weights for both objectives of Maximization of Accessibility and Maximization of Compatibility on a laptop computer with an Intel (R) Core (TM) i5-8250U CPU@1.6 GHz and 8 GB RAM, the 10 fitness values are obtained below. The fitness values (see Table 5) are computed based on different weights combination of the two objectives, i.e., 2 for the objective of accessibility and 1 for the objective of compatibility. In all these experiments, the larger the fitness values are, the better the result is.

Table 5. Fitness value of the solutions based on different weights ( 2 for Accessibility and 1 for Compatibility).

\begin{tabular}{ccccccccccc}
\hline Solution & 1 & 2 & 3 & 4 & 5 & 6 & 7 & 8 & 9 & 10 \\
Fitness Value & 2.4623 & 2.4518 & 2.4615 & 2.4588 & 2.4538 & 2.4580 & 2.4529 & 2.4580 & 2.4615 & 2.4545 \\
\hline
\end{tabular}


It is evident that the fitness values are quite similar, which can somewhat demonstrate the stability and robustness of the model used and experiments conducted.

In addition, the solution maps are also shown below-these solution maps are also quite similar spatially with some minor differences (see Table 6). In addition, the convergence curve for the first experiment (see Figure 4), which is quite same as the convergence curves of the other nine experiments, is also shown below to demonstrate the convergence of the running of the algorithm. These results can also demonstrate the robustness and stability of these experiments as well as the effectiveness of the employed boundary-based GA. Of course, compared to equal weights results, more differences exist between different scenarios, which represent a higher probability of reaching local optimum or could be explained by diverse solutions with similar fitness value. This means the similarity could be considered as part of the fitness function to improve the performance of the optimization process.

Table 6. Results of experiments based on different weights ( 2 for Accessibility and 1 for Compatibility).

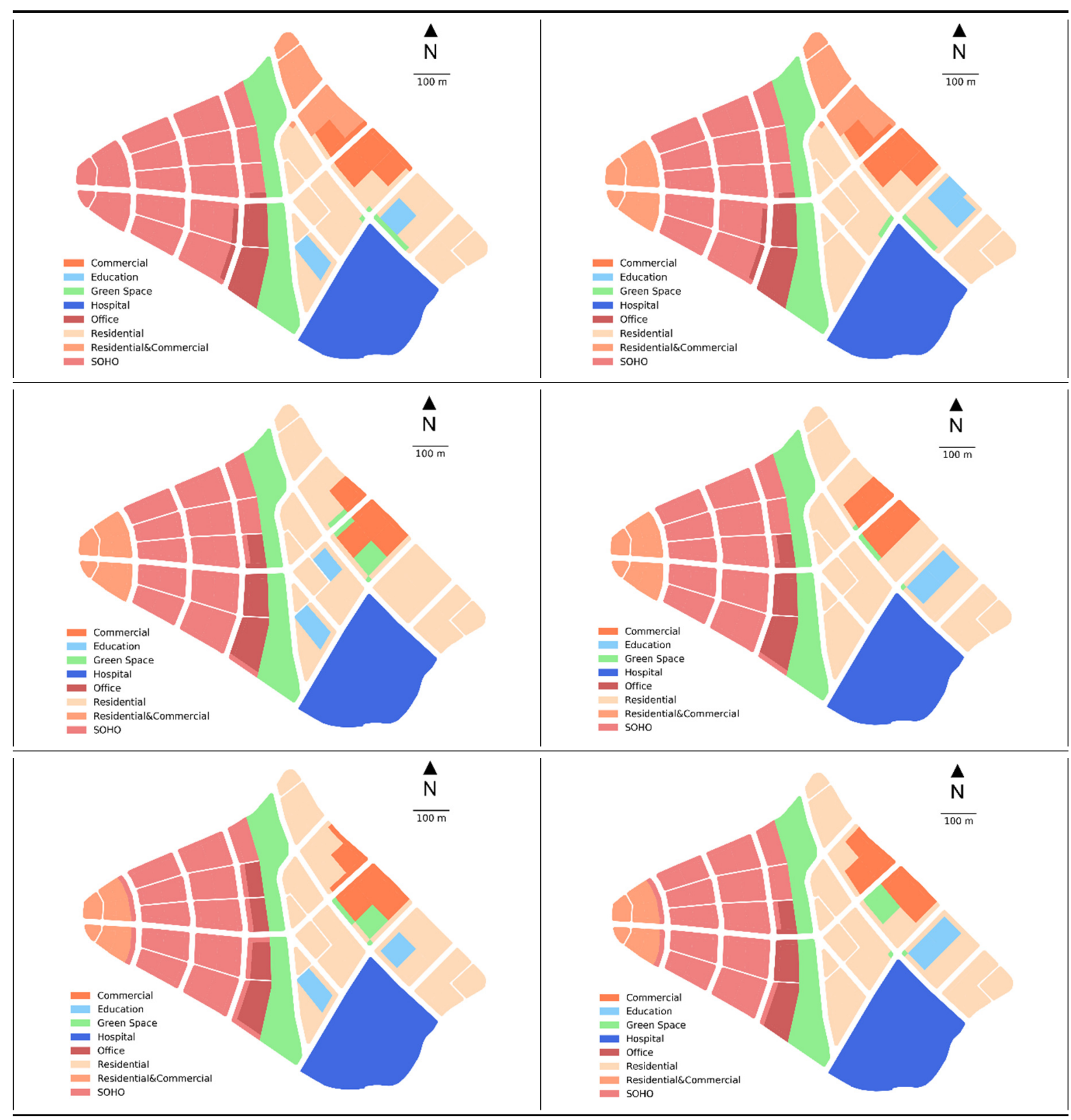


Table 6. Cont.
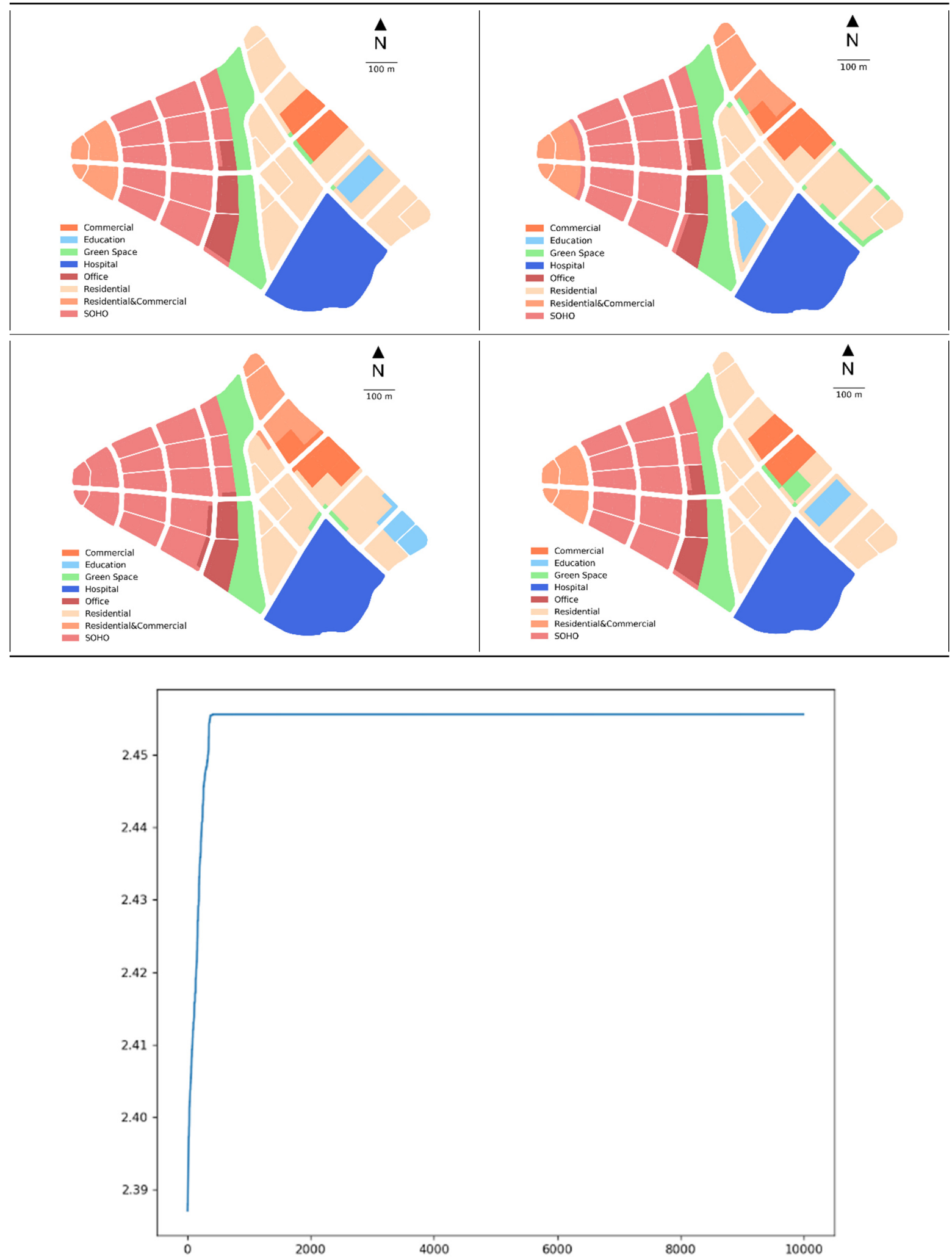

Figure 4. Convergence curve of the first experiment ( $x$ axis refers to the number of iterations, and $y$ axis refers to the fitness value). 


\subsubsection{Comparison with Planned Scenarios}

In this research, we have also invited planners to design two plans according to their preference and interpretation on livability, as well as the context of the research area. Of course, our understanding of livability, as well as these objectives and constraints of our experiments have also referred to these planners' knowledge. The two planned scenarios can be seen as follows with the explanation and justification from the planners (see Table 7).

Table 7. Two planned scenarios with explanation from the planer.

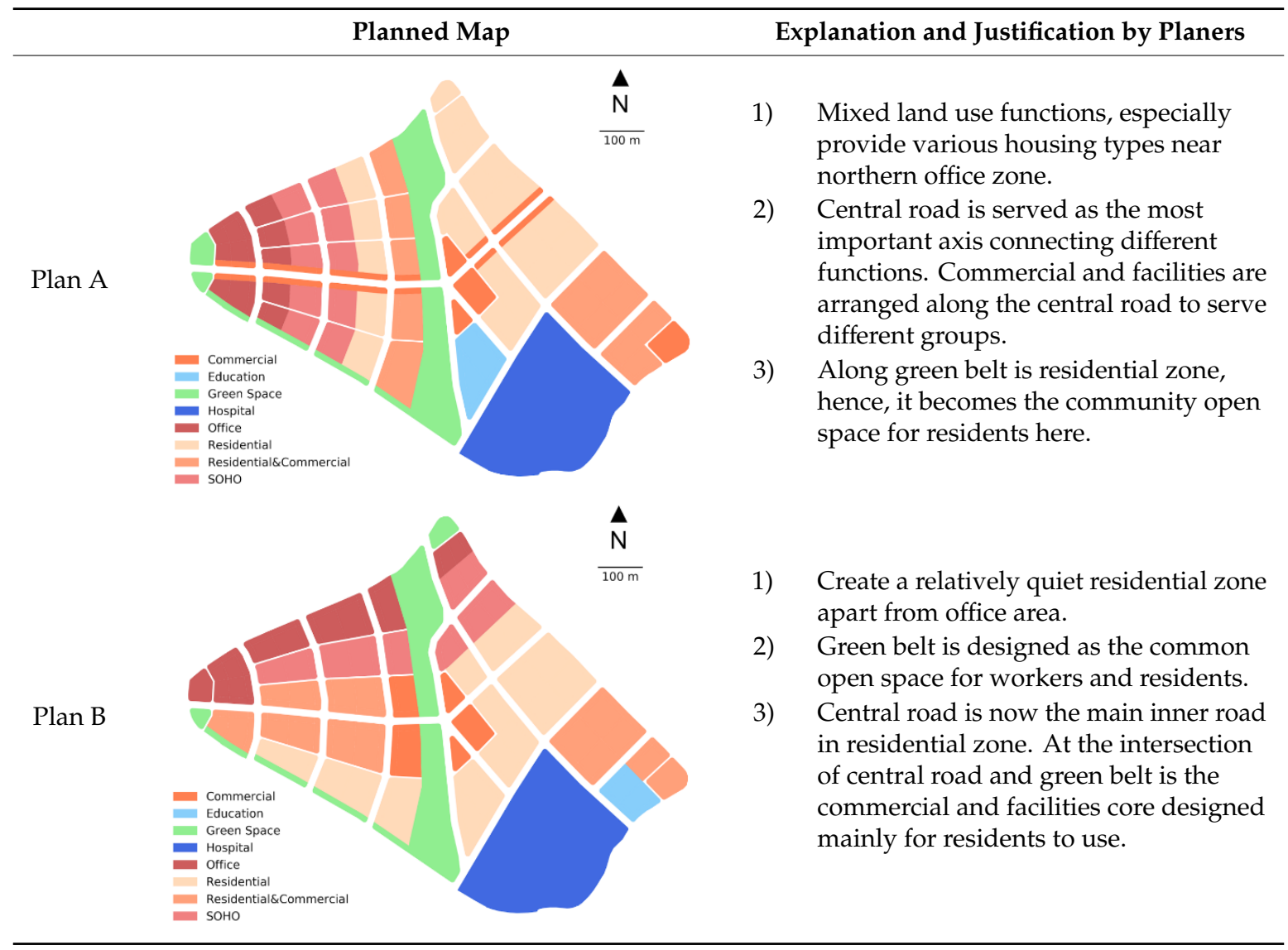

From the above table (see Table 8), it is explicit that even though the planner may declare that they have already considered some of these factors or objectives during the planning process, but the reality is that the planned scenarios are much worse than optimization solutions in terms of the two objectives that have been considered in our model and experiments. Of course, it doesn't mean our optimization model can replace the planner's role, but at least this comparison and all these abovementioned aspects can demonstrate that our proposed model is able to help support the planning process, which is able to provide better solutions quantitatively for the planners' or policymakers' reference and discussion.

Table 8. Comparison results between the two plans from planners and experiments generated plans.

\begin{tabular}{lcccc}
\hline & Plan A & Plan B & Best Solution & Worst Solution \\
\hline Different weights (2 for Accessibility and 1 for & 2.2540 & 2.2783 & $\mathbf{2 . 4 6 2 3}$ & $\mathbf{2 . 4 5 1 8}$ \\
Compatibility) & 1.3781 & 1.3823 & $\mathbf{1 . 4 9 9 1}$ & $\mathbf{1 . 4 9 7 9}$ \\
Equal weights &
\end{tabular}




\section{Reflection, Conclusions, and Future Research}

Land use optimization problems remain a challenge due to the complexity of spatial characteristics and non-linearity of the objectives and constraints. In this research, livability has been quantitatively and comprehensively reviewed and interpreted to contribute to spatial multi-objective land use optimization modelling at first. Second, a spatial multi-objective land use optimization model is constructed based on goal programming and weighted-sum approaches, followed by that a boundary-based GA is adapted to help address the spatial multi-objective land use optimization problem. Last but not least, the model is successfully and effectively applied to the case study in the Central Region of Queenstown Planning Area of Singapore towards livability.

In the case study, the experiments based on equal weights and experiments based on different weights combination have been successfully conducted, which can demonstrate the effectiveness of the spatial multi-objective land use optimization model we have constructed as well as the robustness and reliability of solutions given the similarity between the solutions form 10 repeated experiments in terms of fitness value and the spatial patterns. In addition, the generated solutions maps have also been compared with two real planned scenarios by the planners. The comparison has clearly demonstrated that our proposed or generated solutions maps are much better than these two planned scenarios in terms of fitness values even though the planners have declared that they have probably considered the same objectives as we did. Of course, we cannot draw the conclusion that the computer-generated solutions maps could replace the planners' plan even though the quantitative fitness values outperform these two real planned scenarios, but still, it is evident that our proposed model and the generated planning scenarios are effective in terms of fitness values and the layout of different land use types, which could be utilized as the suggested planning scenarios to support the planners' or decision-makers' planning process. For instance, these generated planning scenarios could help the planners to more quantitatively consider the criteria they want to consider given the limitation of human's ability, and the planners can use these computer-generated planning scenarios as draft plans and design their own plans based on them, or they can refer to these computer-generated solution scenarios to improve their own design with better consideration of these aspects in their mind. In addition, the generated planning scenarios could also initiate some debates between different stakeholders while different preferences or criteria could be more scientifically considered into the planning process. Moreover, the achievement could also help to check the implementation of planning strategies. Specifically, for planners, expressing all the planning ideas clearly and accurately in a draft plan is impossible, especially for large-scale city planning with massive spatial units and criteria. For example, the computer has generated several small green spaces in the residential area. While in planner's design, the focus is mostly on the layout of central green belt, under which circumstance demands for small-scale green space in the residential area are likely to be ignored. Therefore, on the one hand, computer-generated design or planning scenarios can help verify the rationality of planner's design at a large scale, and help to correct small omissions (Note: Small omissions seem insignificant at a city scale, but they are vital to forging the livability of residents in a neighbourhood).

On the other hand, there are still some drawbacks or limitation of this kind of generated planning scenarios. For example, some typical planning strategies employed in the planner's design cannot be reflected in the computer-generated planning scenarios. In the designed planning scenarios, planners have designed a commercial street aiming to increase street's vitality, however, there is no such observation from the generated planning scenario. Of course, it could be somehow integrated into the land use optimization model but the complexity and computing might be a huge challenge. At the same time, these empirical judgments might be able to better contribute to the shaping of urban characteristics, although they are inexhaustible and there might be some omissions. Hence, we would argue or suggest that it would be ideal if planners' design and computer-generated solutions could be integrated and utilized together in an effective manner, so as to supplement each other for a better and more effective "smart planning". 
However, there is still a significant gap between different groups of scholars and planners working in this field and even some bias from some planners on these computer-generated planning scenarios. Therefore, future efforts first should be put into encouraging the collaboration between planners and GIS or computing specialists. Second, it would be much helpful if more empirical judgments on planning could be well quantified and incorporated into the spatial multi-objective land use optimization models for generating more and better planning scenarios to support the practical planning or decision-making process. For example, more effective objectives towards livability could be better discussed and considered, different levels of livable planning scenarios according to the quantified fitness values could also be better defined and incorporated into the practical planning or decision-making process. Third, the interaction and communications between the planners and GIS or computing specialists could be standardized by designing and implementing some effective protocols and interactive planning support systems. All these abovementioned aspects would also be our future research directions.

Author Contributions: Conceptualization, Kai Cao; methodology, Kai Cao and Muyang Liu; validation, Kai Cao, Muyang Liu and Shu Wang; formal analysis, Kai Cao, Muyang Liu and Shu Wang; investigation, Kai Cao and Qiang Meng; resources, Kai Cao and Shu Wang; writing—original draft preparation, Kai Cao, Muyang Liu, Shu Wang and Mengqi Liu; writing — review and editing, Kai Cao, Wenting Zhang, Qiang Meng, and Bo Huang; visualization, Kai Cao, and Muyang Liu. All authors have read and agreed to the published version of the manuscript.

Funding: This research was funded by Singapore Ministry of Education (MOE) Academic Research Fund Tier 1 Grant, grant number R-109-000-229-115.

Conflicts of Interest: The authors declare no conflict of interest.

\section{References}

1. Gough, M.Z. Reconciling Livability and Sustainability. J. Plan. Educ. Res. 2015, 35, 145-160. [CrossRef]

2. WCED. Our Common Future. 29-31. January 1987. Available online: https://sustainabledevelopment.un. org/content/documents/5987our-common-future.pdf (accessed on 30 December 2019).

3. Matthias, R.; Franklin, R.S. Livability for All? Conceptual Limits and Practical Implications. Appl. Geogr. 2013, 49, 18-23.

4. Pacione, M. Urban liveability: A review. Urban Geogr. 2013, 11, 1-30. [CrossRef]

5. Aerts, J.; Van Herwijnen, M.; Janssen, R.; Stewart, T. Evaluating Spatial Design Techniques for Solving Land-use Allocation Problems. J. Environ. Plan. Manag. 2005, 48, 121-142. [CrossRef]

6. Cao, K.; Huang, B.; Wang, S.; Lin, H. Sustainable land use optimization using Boundary-based Fast Genetic Algorithm. Comput. Environ. Urban Syst. 2012, 36, 257-269. [CrossRef]

7. Ligmann-Zielinska, A.; Church, R.L.; Jankowski, P. Sustainable Urban Land Use Allocation With Spatial Optimization. Inter. J. Geogr. Inf. Sci. 2008, 22, 1-18. [CrossRef]

8. Zhang, H.; Zeng, Y.; Jin, X.; Shu, B.; Zhou, Y.; Yang, X. Simulating multi-objective land use optimization allocation using Multi-agent system-A case study in Changsha, China. Ecol. Model. 2015, 320, 334-347. [CrossRef]

9. Cao, K.; Zhang, W.; Wang, T. Spatio-temporal land use multi-objective optimization: A case study in Central China. Trans. GIS 2019, 23, 726-744. [CrossRef]

10. Cao, K.; Batty, M.; Huang, B.; Liu, Y.; Yu, L.; Chen, J. Spatial multi-objective land use optimization: extensions to the non-dominated sorting genetic algorithm-II. Inter. J. Geogr. Inf. Sci. 2011, 25, 1949-1969. [CrossRef]

11. Cao, K. Spatial optimization for sustainable land use planning. In Comprehensive Geographic Information Systems; Elsevier: Amsterdam, The Netherlands, 2017; pp. 244-252.

12. Cao, K.; Ye, X. Coarse-grained parallel genetic algorithm applied to a vector based land use allocation optimization problem: the case study of Tongzhou Newtown, Beijing, China. Stoch. Environ. Res. Risk Assess. 2013, 27, 1133-1142. [CrossRef]

13. Xiao, N.; Murray, A.T. Spatial optimization for land acquisition problems: A review of models, solution methods, and GIS support. Trans. GIS 2019, 23, 645-671. [CrossRef]

14. Yao, J.; Murray, A.T.; Wang, J.; Zhang, X. Evaluation and development of sustainable urban land use plans through spatial optimization. Trans. GIS 2019, 23, 705-725. [CrossRef] 
15. Balsas, C.J.L. Measuring the livability of an urban centre: an exploratory study of key performance indicators. Plan. Pract. Res. 2004, 19, 101-110. [CrossRef]

16. Mullin, J.; Kotval, Z. Measuring the Effectiveness of Downtown Revitalization Strategies. NYCOM Bull. 2003, 23. Available online: https://scholarworks.umass.edu/larp_faculty_pubs/23 (accessed on 30 December 2019).

17. Lynch, K. A Theory of Good City Form; MIT Press: Cambridge, UK, 1981.

18. Antognelli, S.; Vizzari, M. Landscape liveability spatial assessment integrating ecosystem and urban services with their perceived importance by stakeholders. Ecol. Indic. 2017, 72, 703-725. [CrossRef]

19. Burkhard, B.; Kroll, F.; Nedkov, S.; Müller, F. Mapping ecosystem service supply, demand and budgets. Ecol. Indic. 2012, 21, 17-29. [CrossRef]

20. Tallon, A.R.; Bromley, R.D.F. Exploring the attractions of city centre living: evidence and policy implications in British cities. Geoforum 2004, 35, 771-787. [CrossRef]

21. Wang, J.; Su, M.; Chen, B.; Chen, S.; Liang, C. A comparative study of Beijing and three global cities: A perspective on urban livability. Fron. Earth Sci. 2011, 25, 323-327. [CrossRef]

22. Higgs, C.; Badland, H.; Simons, K.; Knibbs, L.D.; Giles-Corti, B. The Urban Liveability Index: developing a policy-relevant urban liveability composite measure and evaluating associations with transport mode choice. Inter. J. Health Geogr. 2019, 18, 1-25. [CrossRef]

23. Litman, T. Developing Indicators for Comprehensive and Sustainable Transport Planning. Trans. Res. Rec. J. Trans. Res. Board 2007, 2017, 10-15. [CrossRef]

24. Miller, H.J.; Witlox, F. Developing context-sensitive livability indicators for transportation planning: a measurement framework. J. Trans. Geogr. 2013, 26, 51-64. [CrossRef]

25. La Rocca, R.A. Soft Mobility and Urban Transformation. TeMA J. Land Use Mobil. Environ. 2009, 3, 85-90. [CrossRef]

26. Abdullahi, S.; Pradhan, B.; Jebur, M.N. GIS-based sustainable city compactness assessment using integration of MCDM, Bayes theorem and RADAR technology. Geocarto Inter. 2015, 30, 365-387. [CrossRef]

27. Ward, D.P.; Murray, A.T.; Phinn, S.R. Integrating spatial optimization and cellular automata for evaluating urban change. Ann. Reg. Sci. 2003, 37, 131-148. [CrossRef]

28. Ligmann-Zielinska, A.; Church, R.L.; Jankowski, P. Spatial optimization as a generative technique for sustainable multiobjective land-use allocation. Inter. J. Geogr. Inf. Sci. 2008, 22, 601-622. [CrossRef]

29. Taleai, M.; Sharifi, M.A.; Sliuzas, R.V.; Mesgari, M.S. Evaluating the compatibility of multi-functional and intensive urban land uses. Inter. J. Appl. Earth Obs. Geoinf. (JAC) 2007, 9, 375-391. [CrossRef]

30. Zhang, H.; Zeng, Y.; Bian, L. Simulating Multi-Objective Spatial Optimization Allocation of Land Use Based on the Integration of Multi-Agent System and Genetic Algorithm. Inter. J. Environ. Res. Public Health 2010, 4, 765-776.

31. Haque, A.; Asami, Y. Optimizing urban land use allocation for planners and real estate developers. Comput. Environ. Urban Syst. 2014, 46, 57-69. [CrossRef]

32. Aerts, J.C.J.H.; Eisinger, E.; Heuvelink, G.B.M.; Stewart, T.J. Using Linear Integer Programming for Multi-Site Land-Use Allocation. Geogr. Anal. 2003, 35, 148-169. [CrossRef]

33. Pareto, V.; Page, A.N. Translation of Manuale di economia politica. In Manual of Political Economy; Oxford University Press: London, UK, 2014.

34. Balling, R.J.; Taber, J.T.; Brown, M.R.; Day, K. Multiobjective urban planning using genetic algorithm. J. Urban Plan. Dev. 1999, 125, 86-99. [CrossRef]

35. Xiao, N.; Bennett, D.A.; Armstrong, M.P. Using evolutionary algorithms to generate alternatives for multiobjective site-search problems. Environ. Plan. A 2002, 34, 639-656. [CrossRef]

36. Janssen, R.; van Herwijnen, M.; Stewart, T.J.; Aerts, J.C. Multiobjective decision support for land-use planning. Environ. Plan. B Plan. Des. 2008, 35, 740-756. [CrossRef]

37. Stewart, T.J.; Janssen, R.; van Herwijnen, M. A genetic algorithm approach to multiobjective land use planning. Comput. Oper. Res. 2004, 31, 2293-2313. [CrossRef]

38. Michalewicz, Z.; Michalewicz, Z. Genetic Algorithms + Data Structures = Evolution Programs; Springer Science + Business Media: Berlin, Germany, 1996. 
39. WorldBank. Singapore-World Bank Data-World Bank Group. Available online: https://data.worldbank. org/country/singapore (accessed on 30 December 2019).

40. NPTD. A Sustainable Population for a Dynamic Singapore. Available online: https://www.strategygroup. gov.sg/media-centre/population-white-paper-a-sustainable-population-for-a-dynamic-singapore (accessed on 30 December 2019).

(C) 2020 by the authors. Licensee MDPI, Basel, Switzerland. This article is an open access article distributed under the terms and conditions of the Creative Commons Attribution (CC BY) license (http://creativecommons.org/licenses/by/4.0/). 